\title{
CFD Simulation of Air-conditioning System in the Public Area of a Metro Station and Research on Energy-saving Operation Scheme
}

\author{
Yin Hua ${ }^{1,}$, , Guo Huafang ${ }^{1, b}$, Lin Zhenrong ${ }^{1, c}$, Zeng Bo ${ }^{2, d}$ \\ ${ }^{1}$ Key Laboratory of Renewable Energy, Guangzhou Institute of Energy Conversion, Chinese \\ Academy of Science, No. 2 Nengyuan Rd. Wushan, Tianhe District, Guangzhou 510640, PR China; \\ ${ }^{2}$ Guangzhou Nikey Electric Co., Ltd, Guangzhou 510640, PR China \\ ayinhua@ms.giec.ac.cn, bouohf@ms.giec.ac.cn, ${ }^{\mathrm{a}}$ linzr@ms.giec.ac.cn, \\ dnikey_002@nikeychina.com
}

Keywords: Metro Station; Air-conditioning System; CFD; Energy-saving Analysis

Abstract. Computational fluid dynamics (CFD) technology was used to conduct an analog simulation of air distribution on the first underground floor of one metro station. The temperature field distributions of the station hall and platform were obtained under two schemes, namely, fixed air volume and variable air volume (VAV). The energy-saving characteristics of the VAV air-conditioning system were analyzed, and corresponding suggestions for improvement were proposed.

\section{Introduction}

All-air systems are generally used in the public areas of metro stations. On the condition that normal metro operation and passenger comfort are guaranteed, an optimal energy-saving and substantially efficient operation scheme of air-conditioning systems should be formulated based on the station's demand for cooling load $[1,2]$. The current study proposed a variable air volume (VAV) air-conditioning system by performing an analytical calculation of the meteorological data in Guangzhou and thermal load in a public area of a metro station. The proposed VAV air-conditioning system is economical and energy-saving, as well as guarantees comfort in the station. The feasibility of this research scheme was verified through a numerical calculation method, which was used to perform an analog verification of the ventilation and air conditioning systems in the summer season.

\section{Project Profile}

The station under study is the Higher Education Mega Center South., which is a transfer station between the No. 4 and 7 lines of Guangzhou Metro. A side island-type transfer mode, which is located on the second underground floor, is adopted in this station. The station hall and platform of the No. 4 line are located on the first underground floor, while the platform of the No. 7 line is located on the second underground floor. The first underground floor is divided into two areas that are connected through a street in the middle. A shielding gate system is used for the platform. Given that the station hall and platform of the No. 4 line are on the first underground floor, the first and second underground floors are provided with two sets of independent, primary return air-conditioning systems. The CFD simulation and analysis conducted in this study focused exclusively on the public area of the first underground floor.

\section{Design Parameters and Load Calculation of the Air-conditioning System}

Design Parameters outside the Station. The calculated dry-bulb temperature of the air conditioner outside the station, wet-bulb temperature of the air conditioner outside the station, and temperature outside the ventilation room in the summer were $32.5,26.9$, and $31.0^{\circ} \mathrm{C}$, respectively.

Calculation Standard and Parameters of the Air-conditioning Load inside the Station. (1) Design parameters inside the station: designed temperature and humidity: $\mathrm{t}=27.0{ }^{\circ} \mathrm{C}, \varphi=45 \%-70 \%$; air supply temperature difference: $9.0^{\circ} \mathrm{C}$. (2) Calculation parameters of fresh air: the maximum 
values of the following cases were considered the minimum fresh air volume in the air-conditioning season: $12.6 \mathrm{~m}^{3} /$ (person.h), air leakage of station shielding gate, and $15 \%$ of the total delivered air volume. The minimum fresh air volume in the non-air-conditioning season was calculated to be at least $30 \mathrm{~m}^{3}$ /(person.h). (3) Air quality standard: $\mathrm{CO}_{2}$ concentration $<1.5 \%$; dust concentration $<0.25$ $\mathrm{mg} / \mathrm{m}^{3}$.

Calculation of Humid and Thermal Loads. The humid and thermal loads in the public area of the station include the thermal and humid loads of the personnel, fresh air load, equipment heat dissipating capacity, lighting load, humidity and heat dissipating capacities of the envelop structure, permeation heats at the exit and entrance, permeation heat of the shielding gate, and heat transfer capacity of the shielding gate. In 2032, the passenger of the No. 4 line embarkation at peak time is projected to be 13,400 people/h, whereas the passenger debarkation flow at peak time is expected to be 7,210 people/h. The future passenger flow of the No. 7 line is projected to be the same as that of the No. 4 line. The passenger flow transfer coefficients of the No. 4 and 7 lines are both 0.6. The personnel heat dissipation is $182 \mathrm{~W} /($ person.h) and humidity dissipation is $193 \mathrm{~g} /($ person.h). The passenger flow clustering coefficient is 0.9 . The standing times of the passenger embarkation flow in the station hall and platform are assumed to be $1.5 \mathrm{~min}$ and $2.5 \mathrm{~min}$, respectively, and those of the passenger debarkation flow are both $1.5 \mathrm{~min}$. The passenger flow density coefficients at different times are available in the literature [3]. The unit area loads at the entrance and exit are both $200 \mathrm{~W} / \mathrm{m}^{2}$, and the unit lighting power is $20 \mathrm{~W} / \mathrm{m}^{2}$. The equipment load is calculated based on power and quantity [4]. The heat dissipating capacity of the envelop structure can be neglected as the margin of the air conditioner load [5]. The thermal load of the shielding gate includes heat transfer and permeation. The heat transfer coefficient of the heat transfer component is $5.7 \mathrm{~W} /\left(\mathrm{m}^{2} \cdot{ }^{\circ} \mathrm{C}\right)$, whereas the permeation load of the shielding gate is calculated based on the $7 \mathrm{~m}^{3} / \mathrm{s}$ air leakage.

Table 1 shows the hour-by-hour residual heat quantity and residual humidity quantity of this station on a typical summer day. The maximum residual heat quantity and residual humidity quantity in the morning peak are $563.86 \mathrm{~kW}$ and $311.78 \mathrm{~kg} / \mathrm{h}$, respectively. The air state point (i.e., $27^{\circ} \mathrm{C}, 57 \%$ ) inside the station is already known. Accordingly, the air supply quantity is $111,630 \mathrm{~m}^{3} / \mathrm{h}$ (i.e., the error between this quantity and the designed value is $-0.33 \%$ ) based on the residual heat quantity, residual humidity quantity, and air supply temperature difference (i.e., $9{ }^{\circ} \mathrm{C}$ ) in the morning peak. The cooling method that involves a fixed temperature and fixed air volume is adopted in this station. On the basis of the calculation parameters of fresh air, the fresh air volume on the first underground floor is the value of the air leakage of the shielding gate added to the permeated air volumes at the exit and entrance $\left(35,640 \mathrm{~m}^{3} / \mathrm{h}\right)$. The cooling load on the first underground floor in the evening peak is 882.19 $\mathrm{kW}$ (i.e., the error between this quantity and the designed value is $1.42 \%$ ).

Table 1 Hour-by-Hour Residual Heat Quantity and Residual Humidity Quantity in the Public Area

\begin{tabular}{|c|c|c|c|c|c|c|c|c|c|}
\hline Time & $6: 00$ & $7: 00$ & $8: 00$ & $9: 00$ & $10: 00$ & $11: 00$ & $12: 00$ & $13: 00$ & $14: 00$ \\
\hline $\begin{array}{c}\text { Residual heat } \\
\text { quantity (kW) }\end{array}$ & 327.45 & 462.95 & 563.86 & 477.36 & 399.52 & 387.99 & 399.52 & 393.96 & 388.19 \\
\hline $\begin{array}{c}\text { Residual humidity } \\
\text { quantity (kg/h) }\end{array}$ & 61.08 & 204.77 & 311.78 & 220.06 & 137.51 & 125.28 & 137.51 & 131.40 & 125.28 \\
\hline $\begin{array}{c}\text { Cooling load } \\
(\mathrm{kW})\end{array}$ & 546.61 & 705.17 & 834.88 & 776.25 & 723.05 & 736.66 & 769.80 & 780.40 & 782.78 \\
\hline Time & $15: 00$ & $16: 00$ & $17: 00$ & $18: 00$ & $19: 00$ & $20: 00$ & $21: 00$ & $22: 00$ & $23: 00$ \\
\hline $\begin{array}{c}\text { Residual heat } \\
\text { quantity (kW) }\end{array}$ & 388.19 & 382.42 & 477.56 & 535.23 & 463.15 & 419.90 & 365.13 & 344.94 & 307.46 \\
\hline $\begin{array}{c}\text { Residual humidity } \\
\text { quantity (kg/h) }\end{array}$ & 125.28 & 119.17 & 220.06 & 281.21 & 204.77 & 158.91 & 100.82 & 79.42 & 39.68 \\
\hline $\begin{array}{c}\text { Cooling load } \\
(\mathrm{kW})\end{array}$ & 781.04 & 759.03 & 864.13 & 882.19 & 782.82 & 713.39 & 639.86 & 606.99 & 558.51 \\
\hline
\end{tabular}




\section{Simulation of the Air-conditioning System of the Station}

Model Establishment. The first underground floor measured $101.45 \mathrm{~m}$ in length, $77.40 \mathrm{~m}$ in width, and $4 \mathrm{~m}$ in height (see Fig. 1). Accordingly, 59 and 7 air inlets that measured $500 \mathrm{~mm} \times 300$ $\mathrm{mm}$ and $800 \mathrm{~mm} \times 200 \mathrm{~mm}$, respectively, as well as 30 exhaust outlets that measured $600 \mathrm{~mm} \times 300$ $\mathrm{mm}$, were set at the ceiling. This study simplified the model to improve the calculation efficiency on the condition that the calculation results were not influenced.

(1) The space occupied by the structural support pillars is relatively smaller than the space occupied by the station. Such disparity in space would not influence air distribution; thus, it was neglected in the modeling.

(2) Human models were simplified. One $2 \times 3 \times 1.7$ human model was set in front of each ticket-selling machine (total of three models). One $6 \times 3 \times 1.7$ human model was set at each brake (total of four models). One $5 \times 4 \times 1.7$ human model was set at each escalator connected to the second underground floor (total of two models). One $2.5 \times 4 \times 1.7$ human model was set at each escalator connected to the street (total of two models). One $1.5 \times 1.2 \times 1.7$ human model was set at each of the two sides of the shielding gate (total of four models at two sides). One $2 \times 1.2 \times 1.7$ human model was set at each of the two sides (total of four models at two sides), followed by eight $3 \times 1.2 \times 1.7$ human models (total of 16 models at two sides). One $2.5 \times 4 \times 1.7$ human model was set at one-third and two-thirds of the street (total of two models).

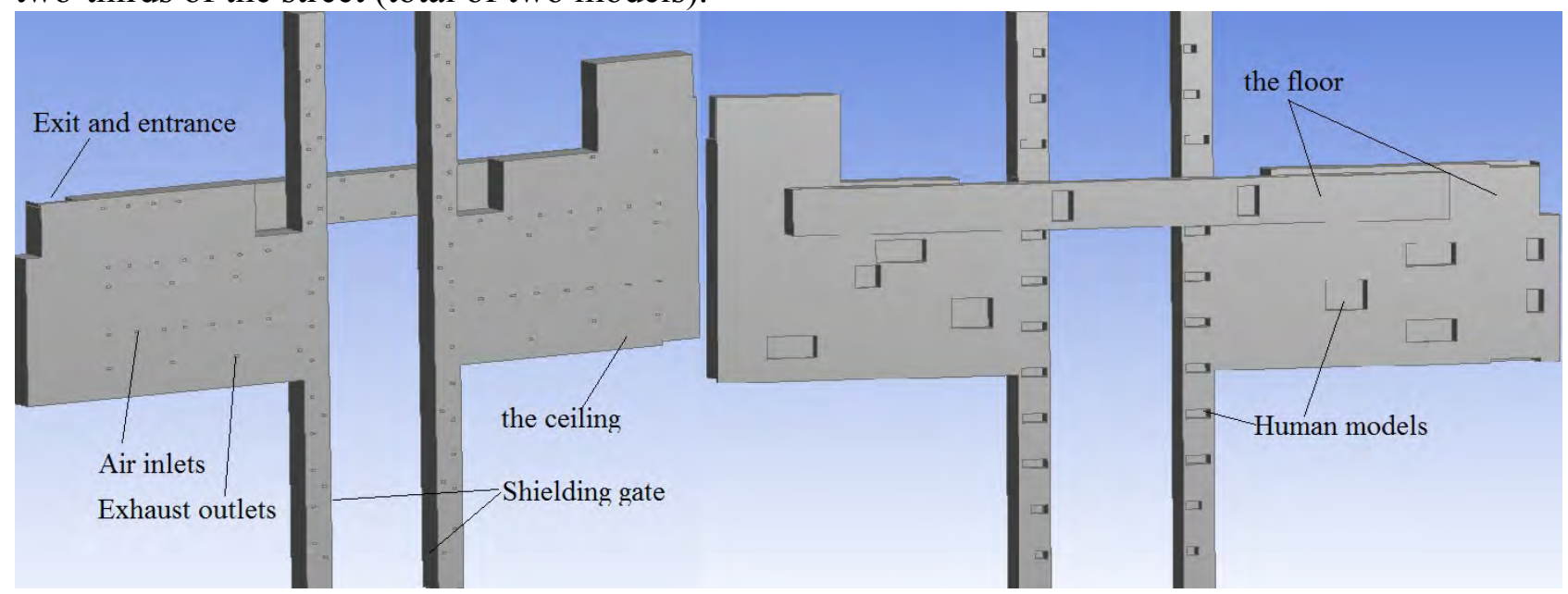

Fig. 1 Construction Drawing of the First Underground Floor

Boundary Conditions. The heat dissipation positions of the illumination, advertising board, indicator, and TV were arranged at the ceiling (total of $90.38 \mathrm{~kW}$ ). By contrast, those of the escalator, ticket-selling machine, brake, recharge machine, and communication equipment were arranged on the floor (total of $59 \mathrm{~kW}$ ). Personnel loads were set on the side surfaces of the human models; the envelop structure only showed humidity dissipation quantity and no heat dissipation load. Meanwhile, no heat exchange was observed between the public area and the area of the equipment and management rooms. Thus, these areas were treated as heat-insulating surfaces. Heat conduction and leakage were $109.58 \mathrm{~kW}$ at the shielding gate. The wall surface temperature of the envelop structure was $27^{\circ} \mathrm{C}$. The air supply temperature under the air-conditioning conditions was $18{ }^{\circ} \mathrm{C}$. A total of $16.59 \mathrm{~kW}$ heat permeation was observed at the exit and entrance. The air supply velocity at the air supply outlet was $3.11 \mathrm{~m} / \mathrm{s}$.

Model Meshing and Solver Parameter Setting. This study adopted the method for defining the meshing size function to guarantee the mesh quality of the model. Meanwhile, mesh quantity was unlikely to be excessively large. First, the meshes of the significant surveyed surfaces (e.g., surfaces of the air inlets and exhaust outlets, as well as the heat flow surfaces with large heat flow) were divided into small sizes, thereby enabling the mesh densities on these surfaces to be relatively high. When the mesh function was defined, the meshes were divided from these critical surfaces toward the surrounding space at 1.1-fold growth rate. A total of 4,586,496 meshes and 846,589 nodes were generated after the calculation. 


\section{Simulation Result of the Air Distribution and Scheme Optimization}

Simulation Result Analysis of the Original Scheme. Only the air-conditioning conditions in the summer were used due to the limited length of this study. The analog CFD calculation and analysis of the air-conditioning conditions were conducted at the representative 6:00, 8:00, and 13:00 time frames on the condition that the air supply temperature difference $\left(9^{\circ} \mathrm{C}\right)$ and air supply volume $\left(111,630 \mathrm{~m}^{3} / \mathrm{h}\right)$ were guaranteed to be unchanged. The temperature field distributions of the first underground floor of the station could be obtained based on the simulation results. For convenience, two representative characteristic sections were selected for analysis: vertical section $(\mathrm{y}=9.7 \mathrm{~m})$ and horizontal section $(\mathrm{z}=1.75 \mathrm{~m})$.

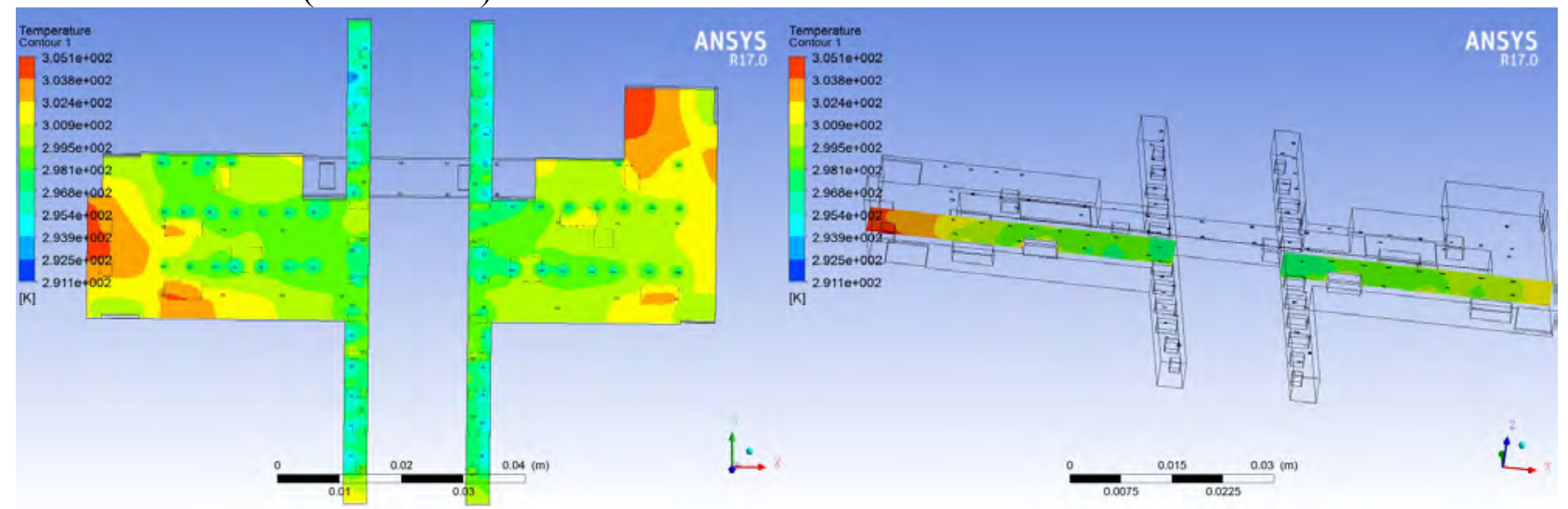

Fig. 2 Temperature field distributions of the station hall and platform at 8:00

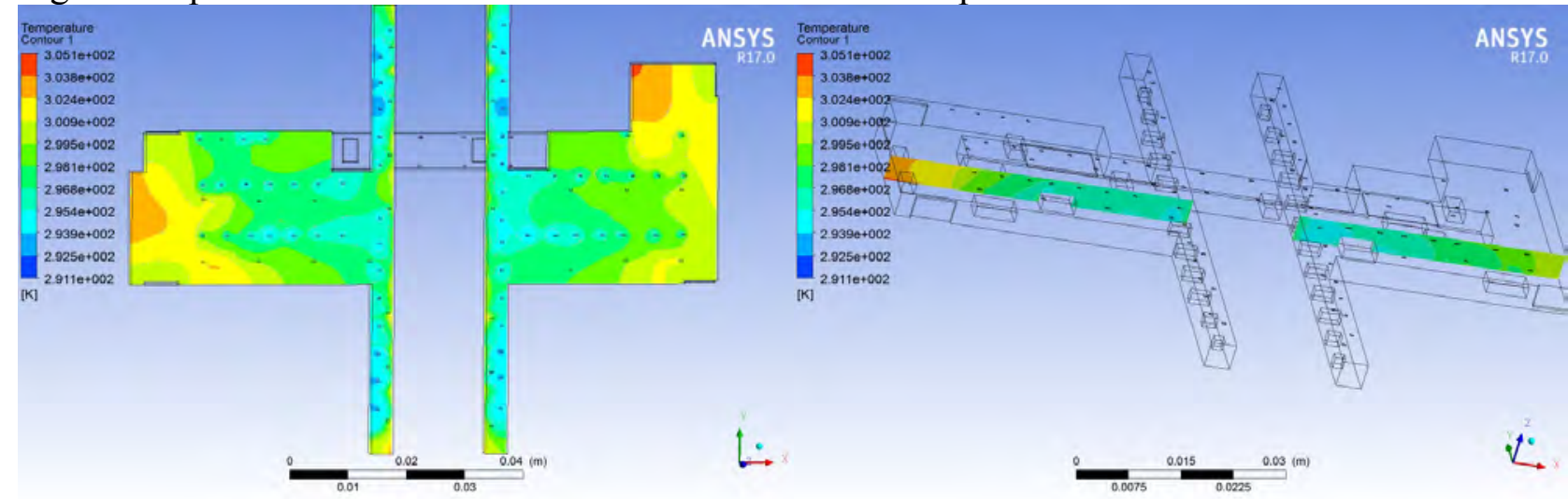

Fig. 3 Temperature field distributions of the station hall and platform at 8:00

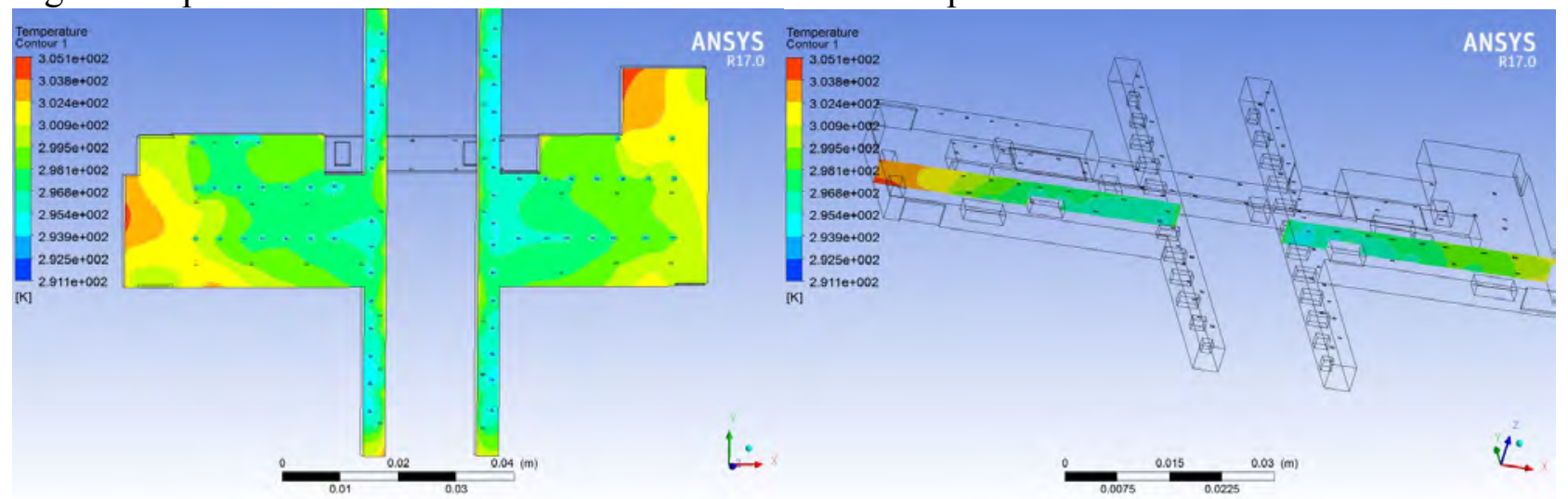

Fig. 4 Temperature field distributions of the station hall and platform at 13:00

The highest temperature at $8: 00$ reached $31.5^{\circ} \mathrm{C}$, whereas the average temperature was merely $27.0^{\circ} \mathrm{C}$ (see Fig. 2). The reason for the excessively high local temperature was the relatively few passengers and lack of airport arrangement in these places. The highest temperatures at 6:00 and 13:00 were $30.2{ }^{\circ} \mathrm{C}$ and $30.9{ }^{\circ} \mathrm{C}$ (see Figs. 3 and 4), respectively. By contrast, the average temperatures were partially low at $25.3^{\circ} \mathrm{C}$ at $6: 00$ and at $25.8^{\circ} \mathrm{C}$ at 13:00. The VAV system should be adopted to reduce the energy consumption of the air-conditioning system. 
Optimization Scheme and Its Simulation Results. The simulation analysis reveals that if constant air volume (CAV) was used, then the temperature inside the station would be partially low in non-morning and evening peaks. Moreover, the simulation results show that the air supply volume of the air conditioners should be adjusted in a timely manner based on the changes in the hour-by-hour cooling load to reduce energy consumption. Table 1 shows the hour-by-hour residual heat quantity and residual humidity quantity. Table 2 shows the hour-by-hour air supply volumes of the first underground floor. The CFD simulation results under air-conditioning conditions at 6:00 and 13:00 (with the adopted VAV air-conditioning system) are shown in Figs. 5 and 6, respectively. The average and highest temperatures at $6: 00$ were $26.9{ }^{\circ} \mathrm{C}$ and $31.4^{\circ} \mathrm{C}$, respectively; and those at 13:00 were $27.0^{\circ} \mathrm{C}$ and $31.5^{\circ} \mathrm{C}$. These results indicate that the application of the VAV air-conditioning system in the metro station is feasible.

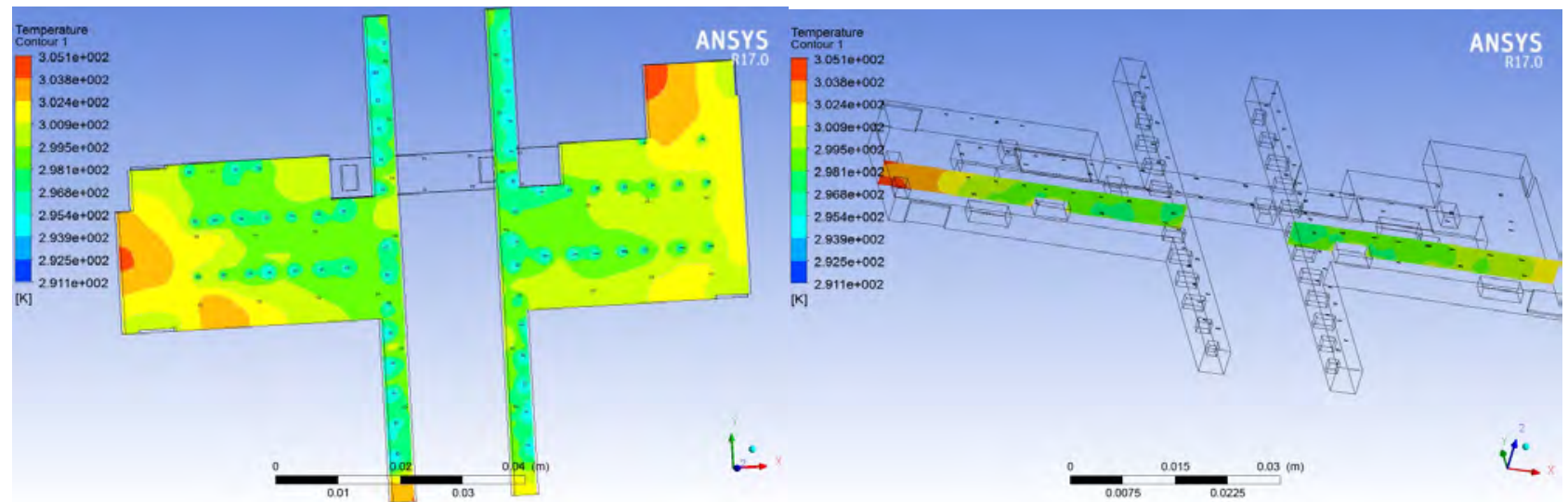

Fig. 5 Temperature field distributions of the station hall and platform at 6:00 (VAV)

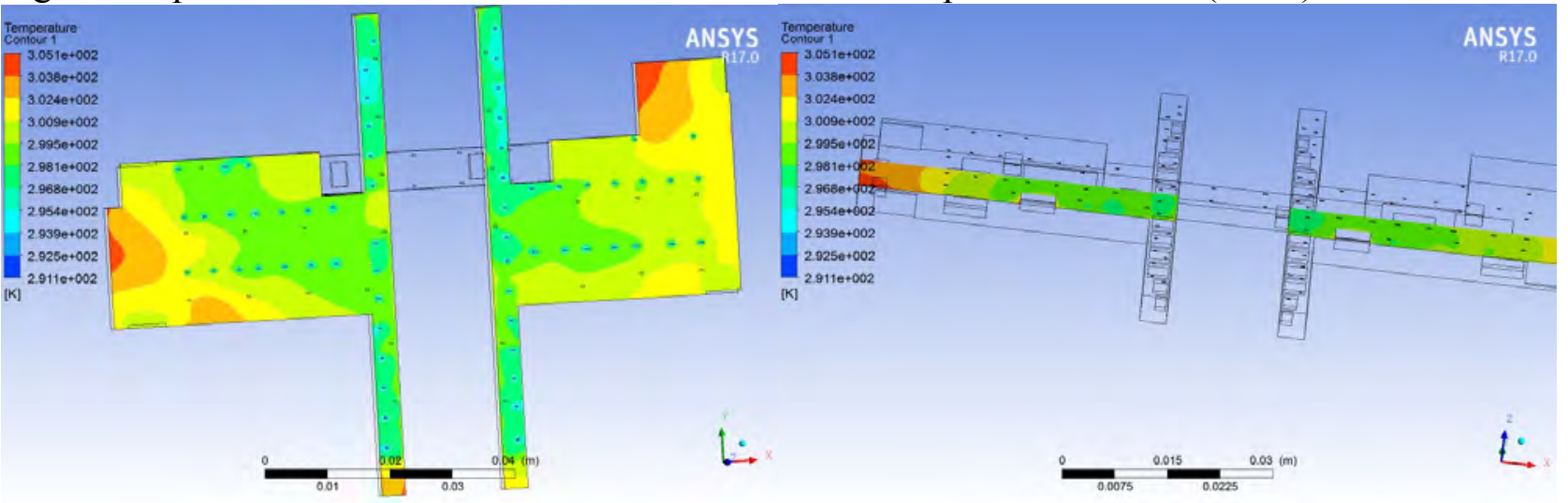

Fig. 6 Temperature field distributions of the station hall and platform at 13:00 (VAV)

Table 2 Hour-by-Hour Air Supply Volume on the First Underground Floor

\begin{tabular}{|c|c|c|c|c|c|c|c|c|c|}
\hline Time & $6: 00$ & $7: 00$ & $8: 00$ & $9: 00$ & $10: 00$ & $11: 00$ & $12: 00$ & $13: 00$ & $14: 00$ \\
\hline $\begin{array}{c}\text { Air supply volume } \\
\left(\mathrm{m}^{3} / \mathrm{h}\right)\end{array}$ & 92160 & 103320 & 111630 & 104490 & 98100 & 97170 & 98100 & 97710 & 97230 \\
\hline Full load ratio (\%) & 82.56 & 92.56 & 100.00 & 93.60 & 87.88 & 87.05 & 87.88 & 87.53 & 87.10 \\
\hline Time & $15: 00$ & $16: 00$ & $17: 00$ & $18: 00$ & $19: 00$ & $20: 00$ & $21: 00$ & $22: 00$ & $23: 00$ \\
\hline $\begin{array}{c}\text { Air supply volume } \\
\left(\mathrm{m}^{3} / \mathrm{h}\right)\end{array}$ & 97230 & 96750 & 104580 & 109320 & 103380 & 99840 & 95310 & 93660 & 90570 \\
\hline Full load ratio (\%) & 87.10 & 86.67 & 93.68 & 97.93 & 92.61 & 89.44 & 85.38 & 83.90 & 81.13 \\
\hline
\end{tabular}

Energy-saving and Energy Efficiency Analysis. (1) Energy-saving analysis of the VAV air-conditioning system. Frequency conversion technology was used to regulate the revolving speed of the draught fan. The reduced theoretical value after regulation could be calculated through the following equation [6]: 


$$
\begin{aligned}
& \frac{N_{2}}{N_{1}}=\left(\frac{Q_{2}}{Q_{1}}\right)^{3} \\
& \Delta N=N_{1}-N_{2} \\
& \Delta N=N_{1}\left[1-\left(\frac{Q_{2}}{Q_{1}}\right)^{3}\right] .
\end{aligned}
$$

The total power consumption of the draught fans under full-load design conditions was $78 \mathrm{~kW}$. Table 3 shows the energy-saving amount and reduction rate of energy consumption of the air supply draught fans under air-conditioning conditions in the summer.

Table 3 Energy-saving Amount and Reduction Rate of the Energy Consumption of the Air Supply Draught Fans of the VAV Air-conditioning System

\begin{tabular}{|c|c|c|c|c|c|c|c|c|c|}
\hline Time & $6: 00$ & $7: 00$ & $8: 00$ & $9: 00$ & $10: 00$ & $11: 00$ & $12: 00$ & $13: 00$ & $14: 00$ \\
\hline Energy-saving (kW) & 34.11 & 16.15 & 0 & 14.03 & 25.06 & 26.55 & 25.06 & 25.69 & 26.46 \\
\hline Energy-saving rate (\%) & 43.73 & 20.71 & 0.00 & 17.99 & 32.13 & 34.04 & 32.13 & 32.94 & 33.92 \\
\hline Time & $15: 00$ & $16: 00$ & $17: 00$ & $18: 00$ & $19: 00$ & $20: 00$ & $21: 00$ & $22: 00$ & $23: 00$ \\
\hline Energy-saving (kW) & 26.46 & 27.22 & 13.87 & 4.74 & 16.04 & 22.20 & 29.45 & 31.93 & 36.34 \\
\hline Energy-saving rate (\%) & 33.92 & 34.90 & 17.78 & 6.08 & 20.57 & 28.46 & 37.76 & 40.94 & 46.59 \\
\hline
\end{tabular}

Table 3 shows that after the adoption of the VAV air-conditioning system, the average decrement of the power consumption of the draught fans was approximately $22.30 \mathrm{~kW}$. This study only analyzed the energy-saving situation of the draught fans during the operating process of the VAV air-conditioning system. Energy conservation also occurs in the cold-source system with the adoption of the VAV air-conditioning system. Therefore, the VAV air-conditioning system showed a favorable effect on the energy conservation of the metro station.

(2) Comparison of the exergy efficiency analysis results of the CAV and VAV air-conditioning systems. The primary return air-conditioning system mainly includes a mixing chamber, surface air cooler, reheater, draught fan, and terminal equipment. The primary return air-conditioning system in the present study was considered in its entirety for the exergy efficiency analysis. System exergy efficiency is defined as the ratio of usable exergy to input exergy. Thus, exergy efficiency in the refrigeration period is written as follows [7]:

$$
\eta=\frac{E x_{c o o l}}{E x_{i n}}
$$

As

$$
\begin{aligned}
& E x_{\text {cool }}=Q_{c} \times\left(\frac{T_{i 0}}{T_{r c}}-1\right) \\
& E x_{i n}=E x_{L, i n}+E x_{R, \text { in }}+W_{s}+E x_{x i n}+E x_{h u i} .
\end{aligned}
$$

The following equation can be obtained:

$$
\eta=\frac{Q_{c} \times\left(\frac{T_{i 0}}{T_{r c}}-1\right)}{E x_{L, i n}+E x_{R, i n}+W_{s}+E x_{x i n}+E x}
$$

where $\mathrm{Ex}_{\mathrm{cool}}$ is the exergy in the refrigeration period $\mathrm{kW}$; $\mathrm{Q}_{\mathrm{C}}$ is the cooling consumption per hour of the air conditioner; $\mathrm{T}_{\mathrm{i} 0}$ is the outdoor temperature changing hour by hour $\mathrm{K} ; \mathrm{T}_{\mathrm{rc}}$ is the temperature inside the station in the refrigeration period $\mathrm{K}$; Ex $\mathrm{in}_{\text {in }}$ includes the cold exergy $\mathrm{Ex}_{\mathrm{L}}$, in added by the air cooler to cool the air, the hot exergy $\mathrm{Ex}_{\mathrm{R}}$, in added by the reheater to heat the air to the appropriate air supply temperature, power consumption $\mathrm{W}_{\mathrm{S}}$ of the air supply draught fan, and the exergy values $\mathrm{Ex}_{\mathrm{xin}}$ 
and $\mathrm{Ex}_{\text {hui }}$ of the fresh air and return air, respectively. Table 4 presents the hour-by-hour exergy efficiencies of the CAV and VAV air-conditioning systems.

Table 4 Hour-by-Hour Exergy Efficiencies of the Air-conditioning System in the Station

\begin{tabular}{|c|l|r|r|r|r|r|r|r|r|c|}
\hline \multicolumn{2}{|c|}{ Time } & $6: 00$ & $7: 00$ & $8: 00$ & $9: 00$ & $10: 00$ & $11: 00$ & $12: 00$ & $13: 00$ & $14: 00$ \\
\hline \multirow{2}{*}{ Exergy efficiency } & CAV (\%) & 3.53 & 4.84 & 5.94 & 5.73 & 5.35 & 5.49 & 5.77 & 5.84 & 5.83 \\
\cline { 2 - 11 } & VAV (\%) & 4.87 & 5.46 & 5.94 & 6.45 & 6.56 & 6.85 & 7.10 & 7.19 & 7.28 \\
\hline \multicolumn{2}{|c|}{ Time } & $15: 00$ & $16: 00$ & $17: 00$ & $18: 00$ & $19: 00$ & $20: 00$ & $21: 00$ & $22: 00$ & $23: 00$ \\
\hline \multirow{2}{*}{ Exergy efficiency } & CAV (\%) & 5.82 & 5.64 & 6.48 & 6.74 & 5.86 & 5.20 & 4.52 & 4.20 & 3.75 \\
\cline { 2 - 10 } & VAV (\%) & 7.26 & 7.02 & 7.43 & 7.27 & 6.74 & 6.27 & 5.83 & 5.53 & 5.11 \\
\hline
\end{tabular}

The exergy and energy efficiencies of the VAV air-conditioning system were higher than those of the CAV air-conditioning system.

\section{Conclusions}

The CFD technology was used to conduct a numerical simulation of the CAV and VAV air-conditioning systems in a public area of a metro station. The temperature field distributions of the air conditioners in the summer under two schemes were obtained. The comparison and analysis results revealed that the VAV air-conditioning system could completely meet the requirements for thermal comfort.

Accordingly, reducing the energy consumption of the draught fans is the key to implementing the VAV air-conditioning system. The results of the system analysis and calculation indicate that the use of the VAV air-conditioning system will enable draught fans to save approximately $22.30 \mathrm{~kW}$ of power consumption on a typical air-conditioning day in the summer. Moreover, the exergy efficiency of the VAV air-conditioning system was higher than that of the CAV air-conditioning system.

\section{Acknowledgments}

This study was financially supported by the Guangzhou Science and Technology Program (2017010160583).

\section{References}

[1] Zh. Yang, L.Q. Yu, F. Ma, M. Shao: J. Tianjin Univ. Vol. 45 (2012), p. 599-603.

[2] X. Ch. Deng, J. Liu: HV \& AC Vol. 40 (2010), p. 102-105.

[3] J. Luo, in: Study on Operation Strategy of Energy-saving in Ventilation and Air conditioning System of Metro, Master Thesis, Guangzhou University, Guangzhou, China (2015).

[4] J. Zhao, in: Study and analysis of Subway Ventilation and Air Conditioning System Energy Consumption, Doctoral Thesis, Wuhan University of Technology, Wuhan, China (2014).

[5] X. C. Zhao: Heating, Ventilating and Air Conditioning Vol. 36 (2006), p. 72-74.

[6] J. B. Chen, Y. H. Wang, W. B. Weng, X. Lin, J. F. Wang: Refrigeration and Air-condition Vol. 5 (2005), p. 53-59.

[7] Y. Zh. Yuan, in: Energy Consumption Study of Central Air Condition System Based on Exergy Analysis, Master Thesis, Nanjing University of Science \& Technology, Nanjing, China (2007). 